J. Dairy Sci. 92:3411-3421

doi:10.3168/jds.2008-1631

(c) American Dairy Science Association, 2009.

\title{
Estimation of variance components and genetic trends for twinning rate in Holstein dairy cattle of Iran
}

\author{
N. Ghavi Hossein-Zadeh, ${ }^{1}$ A. Nejati-Javaremi, S. R. Miraei-Ashtiani, and H. Kohram \\ Department of Animal Science, University College of Agriculture and Natural Resources, University of Tehran, Karaj, Iran
}

\begin{abstract}
Calving records from the Animal Breeding Center of Iran, collected from January 1991 to December 2007 and comprising 1,163,594 Holstein calving events from 2,552 herds, were analyzed using a linear animal model, linear sire model, threshold animal model, and threshold sire model to estimate variance components, heritabilities, genetic correlations, and genetic trends for twinning rate in the first, second, and third parities. The overall twinning rate was $3.01 \%$. Mean incidence of twins increased from first to fourth and later parities: $1.10,3.20,4.22$, and $4.50 \%$, respectively. For first-parity cows, a maximum frequency of twinning was observed from January through April (1.36\%), and second- and third-parity cows showed peaks from July to September (at 3.35 and $4.55 \%$, respectively). The phenotypic rate of twinning decreased from 1991 to 2007 for the first, second, and third parities. Sire predicted transmitting abilities were estimated using linear sire model and threshold sire model analyses. Sire transmitting abilities for twinning rate in the first, second, and third parities ranged from -0.30 to $0.42,-0.32$ to 0.31 , and -0.27 to 0.30 , respectively. Heritability estimates of twinning rate for parities 1, 2, and 3 ranged from 1.66 to $10.6 \%$, 1.35 to $9.0 \%$, and 1.10 to $7.3 \%$, respectively, using different models for analysis. Heritability estimates for twinning rate, obtained from the analysis of threshold models, were greater than the estimates of linear models. Solutions for age at calving for the first, second, and third parities demonstrated that cows older at calving were more likely to have twins. Genetic correlations for twinning rate between parities 2 and 3 were greater than correlations between parities 1 and 2 and between parities 1 and 3 . There was a slightly increasing trend for twinning rate in parities 1,2 , and 3 over time with the analysis of linear animal and linear sire models, but the trend for twinning rate in parities 1,2 , and 3 with threshold animal model analysis was decreased
\end{abstract}

\footnotetext{
Received August 13, 2008.

Accepted March 22, 2009

${ }^{1}$ Corresponding author: nghavi@ut.ac.ir or navid.hosseinzadeh@ gmail.com
}

over the years. There was a significant decreasing trend for twinning rate in parities 1 and 2 over time with the threshold sire model analysis, but the genetic trend for twinning rate in parity 3 with this model of analysis was significant and positive. In general, there were increasing genetic trends for twinning rate from parities 1 through 3 using different models of analysis.

Key words: twinning rate, linear model, threshold model, genetic trend

\section{INTRODUCTION}

Rate of reproduction has a major impact on life-cycle costs of production of different animal species and on their competitiveness for different types of production resources. High-producing dairy cows produce 5 times as much milk protein per unit of feed as beef cattle (Reid et al., 1980).

However, twin birth is disadvantageous for most beef and dairy producers because of its association with several unfavorable effects, including lower potential calf survival and poorer cow reproductive performance (Fricke, 2001). Twinning is also associated with increased dystocia (because of malpresentation), increased incidence of retained placenta, higher mortality rates, frequent occurrence of freemartins, and longer intervals from parturition to first estrus (Kirkpatrick, 2002; Silva del Río et al., 2007).

The results of numerous surveys and studies have generally been consistent in identifying problems associated with twinning, except for dystocia. Inconsistent results for incidence of dystocia may reflect 2 competing dynamics: twinning reduces the incidence of dystocia attributable to large calf size but increases the incidence of dystocia attributable to malpresentation (Kirkpatrick, 2002). Dairy cows may give more milk in the lactation resulting from a twin birth (Syrstad, 1974), but cows calving twins are at greater risk for metabolic disorders, including displaced abomasum and ketosis (Fricke, 2001). In addition, increased frequency of twinning would increase the potential for obtaining more progeny from a genetically superior female, thereby allowing those females to play a larger role in a selection program (Cady and Van Vleck, 1978). The 
Table 1. Summary of pedigree information

\begin{tabular}{lccccccc}
\hline Animals in total & $\begin{array}{c}\text { Inbred } \\
\text { animals }\end{array}$ & Sires & Dams & $\begin{array}{c}\text { Animals } \\
\text { with progeny }\end{array}$ & $\begin{array}{c}\text { Animals } \\
\text { without progeny }\end{array}$ & $\begin{array}{c}\text { Base } \\
\text { animals }\end{array}$ & $\begin{array}{c}\text { Non-base } \\
\text { animals }\end{array}$ \\
\hline 497,216 & 208,201 & 8,007 & 242,176 & 250,183 & 247,033 & 87,444 & 409,772 \\
\hline
\end{tabular}

importance of this condition can be expressed along with the application of technologies controlling the sex of calves. In other words, the use of embryo technologies and sexed semen leads to significantly more female calves. This allows dairy producers to select among the potential dams of their herd and produce dairy replacement heifers from only the genetically superior animals, and it promotes enhanced rates of genetic gains (De Vries et al., 2008).

Individuals with high twinning rates still appear, especially in the Holstein breed. Protection of recessive alleles may explain the repeated occurrence of hightwinning individuals; however, Van Vleck and Gregory (1996) reported no dominance effects for ovulation rate in beef cattle, a trait closely related to twinning. Gregory et al. (1990) concluded that twinning rate is a quantitative trait that has an underlying continuous expression involving many loci. Continued increases in milk production over the last 2 decades in dairy herds have been associated with an increase in twinning rate (Kinsel et al., 1998; Wiltbank et al., 2000). Wiltbank et al. (2000) proposed that high milk production increases steroid metabolism because of an increased blood flow to the digestive tract and the liver. The subsequent metabolism of the steroid estradiol slows the natural decline in FSH, which means that follicles have more time to undergo physiological changes before ovulation (Wiltbank et al., 2000). The lactation number and level of milk production of the cow appear to be positively associated with increased ovulation rate and twinning (Fricke and Wiltbank, 1999; Wiltbank et al., 2000).

Syrstad (1974) estimated the heritability and repeatability of twinning in Norwegian dairy cattle to be $2.2 \pm$ $0.2 \%$ and $6.0 \pm 0.7 \%$, respectively. Additionally, Syrstad (1974) transformed the $2.2 \%$ heritability on a binomial scale to $23 \%$ for an underlying continuous variable using the formula from Van Vleck (1971). This could be an overestimation because twinning occurs less than $20 \%$ of the time (Van Vleck, 1971). Ron et al. (1990) reported the twinning rate in Holsteins to be 4.8 and $6.9 \%$ for second- and third-parity cows, respectively. They estimated heritability to be $10.1 \%$ when using a threshold model, but only $2.2 \%$ when using a linear model. Repeatability estimates were 55 and $30 \%$ for the sire and maternal grandsire models, respectively.

According to Ron et al. (1990), the twinning rate of Holsteins increased from 4.5 to $5.6 \%$ during a 20 - yr period along with increasing milk production. The small estimates of heritability $(<0.10)$ for twinning rate, which agreed with the literature reviewed by Gregory et al. (1990), as well as the long generation interval and high resource requirement to obtain measures of the twinning rate, led to the suggestion to use ovulation rate in pubertal heifers to select indirectly for twinning rate (Echternkamp et al., 1990). In most analyses, repeatability has been estimated to be less than heritability; this has been postulated to arise from small negative environmental covariances in adjacent gestations or estrous cycles. Generally, most studies involving analyses of field data have reported that heritability of singleparity twinning rate is low, averaging approximately 0.04. Syrstad (1984) estimated heritability for twinning as 0.006 in the first parity, increasing to approximately 0.04 in parities 3 to 5 when using Norwegian data collected from 1978 to 1981. In some countries where male calves from dairy operations are raised for beef production, increasing the twinning rate is one causative effect of increasing beef production. There is much genetic potential to improve dairy production by selection for or against the incidence of twinning, and this highlights

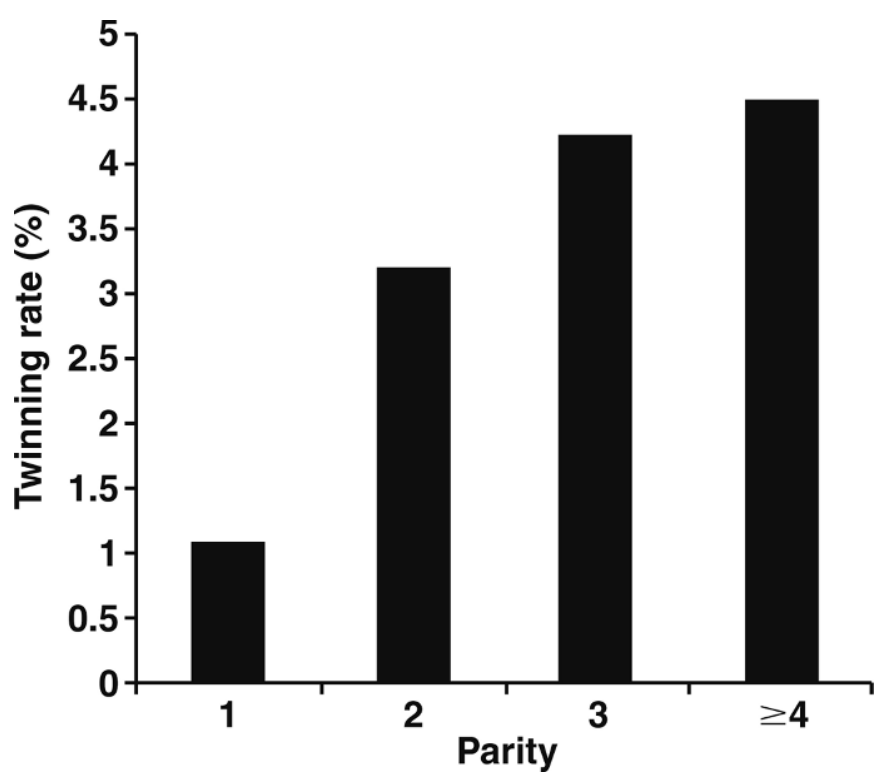

Figure 1. Twinning rate by parity for total data set. The frequency of twinning increased from $1.10 \%$ in parity 1 to $4.50 \%$ in parity 4 and greater. 
the importance of increasing knowledge of the inheritance of twinning. The objectives of this study were to estimate variance components, heritabilities, genetic correlations, and genetic trends for twinning rate by using a linear animal model, linear sire model, threshold animal model, and threshold sire model in the first 3 lactations of Holstein dairy cattle of Iran.

\section{MATERIALS AND METHODS}

\section{Data}

Calving records from the Animal Breeding Center of Iran, collected from January 1991 to December 2007 and comprising 1,163,594 Holstein calving events from 2,552 herds, were included in the initial data set. Twin calvings accounted for $32,082(2.76 \%)$ of the total observations. The majority of the Iranian dairy cattle population consists of several domestic breeds and their crosses with Holsteins. Only approximately 800,000 animals are purebred Holsteins. These are either descendants of the cows originally imported from North America and Europe or Holstein upgrades of domestic breeds over 50 yr. The herds used in this study are among the purebred Holsteins managed under conditions similar to those in most other developed countries. The herds are under official performance and pedigree recording. Artificial insemination is used almost exclusively, and 60 to $80 \%$ of semen is from US and Canadian proven sires (Ghavi Hossein-Zadeh et al., 2008). Information on individual calving events, including herd, cow identification, service sire identification, cow's sire identification, calving date, dry date, parity, multiple births, calf gender, and calving difficulty, were included in the data set. The number of calves born per calving event was coded as a dichotomous variable $(0=$ singleton; 1 = twin). Although both monozygotic and dizygotic twins occur, it was not possible to distinguish

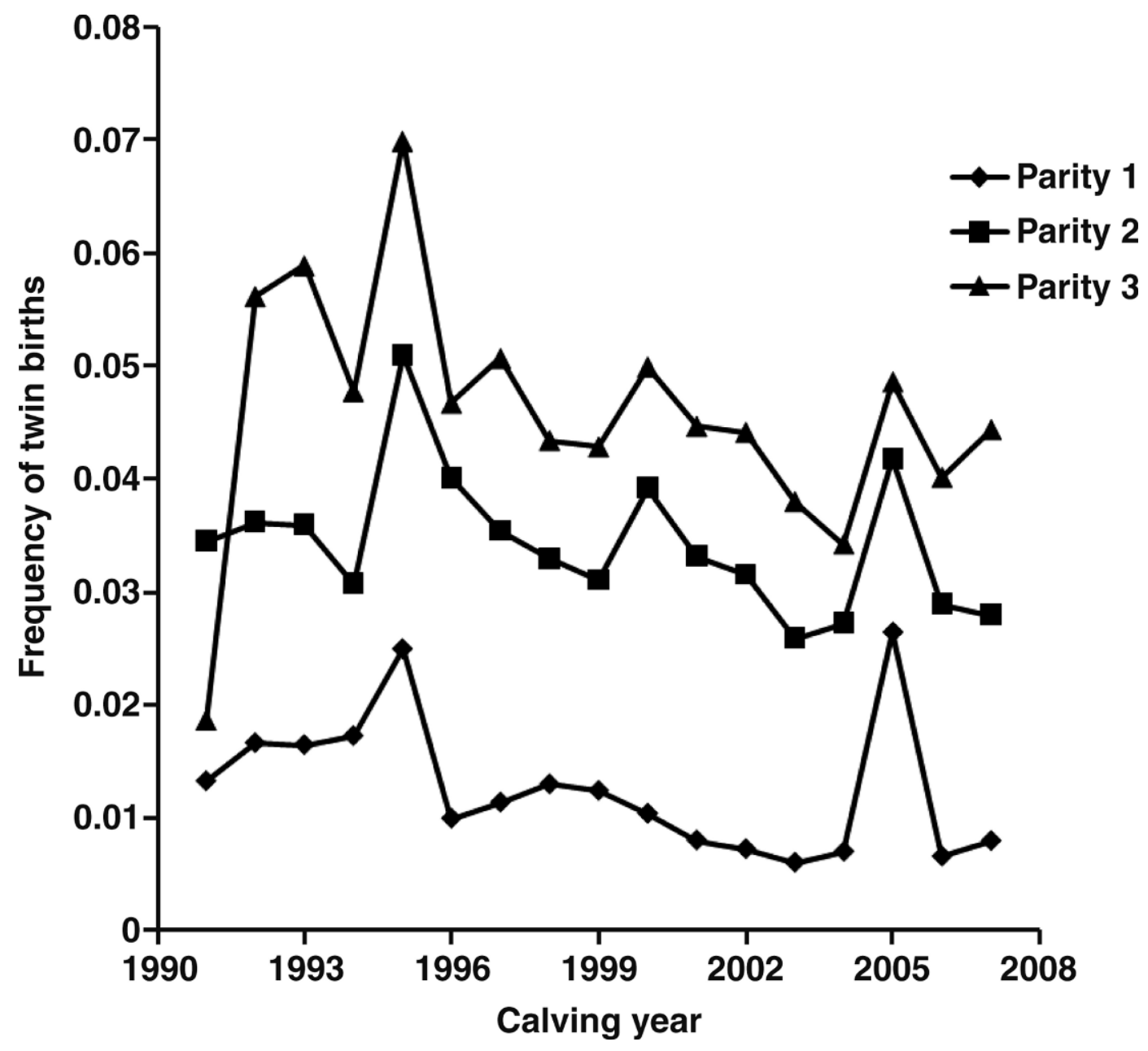

Figure 2. Twinning rate by year of calving for first-, second-, and third-parity cows. Phenotypic rate of twinning decreased slightly from 1991 to 2007 for first, second, and third calvings. 
Table 2. Estimates of variance components and heritability of twinning rate in first, second, and third parities by different models of analysis

\begin{tabular}{|c|c|c|c|c|}
\hline Model of analysis & Item & Parity 1 & Parity 2 & Parity 3 \\
\hline \multirow{2}{*}{ Linear animal } & Residual variance & 0.0246387 & 0.030803 & 0.0409892 \\
\hline & Phenotypic variance & 0.02508884 & 0.03125222 & 0.04144304 \\
\hline \multirow[t]{3}{*}{ Linear sire } & Sire variance & 0.00012591 & 0.00010520 & 0.00012670 \\
\hline & Residual variance & 0.0302516 & 0.0311431 & 0.0413183 \\
\hline & Phenotypic variance & 0.03135751 & 0.03124830 & 0.04144500 \\
\hline \multirow{3}{*}{ Threshold sire } & Residual variance & 1 & 1 & 1 \\
\hline & Phenotypic variance & 1.0271 & 1.0231 & 1.0187 \\
\hline & Heritability $( \pm \mathrm{SE})$ & $0.106 \pm 0.004$ & $0.090 \pm 0.003$ & $0.073 \pm 0.003$ \\
\hline \multirow{4}{*}{ Threshold animal } & Additive variance & 0.0803 & 0.0717 & 0.0575 \\
\hline & Residual variance & 1 & 1 & 1 \\
\hline & Phenotypic variance & 1.0803 & 1.0717 & 1.0575 \\
\hline & Heritability $( \pm \mathrm{SE})$ & $0.074 \pm 0.003$ & $0.067 \pm 0.001$ & $0.054 \pm 0.001$ \\
\hline
\end{tabular}

between them with these data. Therefore, in this study all twin births were assumed to be dizygotic (Johanson et al., 2001). In addition to the data file, a pedigree file was available that contained more than 497,000 cows, of which the first were born in 1963 (Table 1).

\section{Analyses}

Threshold and linear animal models were used, with twinning rate defined as a single or twin birth for each cow with a reported calving date for parities 1,2 , and 3. The model used for analyses was as follows:

$y_{i j k l m n}=\mu+a_{i}+p_{j}+h y_{k}+s e a_{l}+b\left(A g e_{m}-\overline{A g e}\right)+e_{i j k l m n}$,

where $y_{i j k l m n}$ was the observation on calving type (0 for single or 1 for twin) affected by random additive genetic effect of animal $i\left(a_{i}\right)$ in the fixed effects of parity $j\left(p_{j}\right)$, calving in the $k$ th herd-year $\left(h y_{k}\right)$ and in season $l\left(s e a_{l}\right)$, at age of calving $m$ (covariate $A g e_{m}$ ), and the random effect of residual error $\left(e_{i j k l m n}\right)$.

In addition, threshold and linear sire models were used, with twinning rate defined as a single or twin birth for each cow with a reported calving date for parities 1, 2, and 3. The model used for analysis was as follows:

$y_{i j k l m n}=\mu+p_{i}+h y_{j}+s e a_{k}+b\left(A g e_{l}-\overline{A g e}\right)+s_{m}+e_{i j k l m n}$,

where $s_{m}$ is the $m$ th sire of cow $i$, and other terms are as defined above. The $s$ and residual effects were random, whereas $p, h y$, sea, and Age were fixed effects, as with the animal models.

Several linear-linear and threshold-threshold bivariate or pair-wise analyses were carried out for every pair of the traits (twinning in parity 1 with 2,1 with 3 , or 2 with 3 ) to estimate genetic and phenotypic cor- relations for twinning in different parities. The models applied in pair-wise analyses were the same as those fitted for twinning rates of each parity in the univariate analyses.

Only sires of the cows producing calves (maternal effect on twinning) were included in the models. Several reasons explain why sire of the calf (direct effect) was not included in the analysis: service sire had no effect on whether the cow ovulated 1,2, or more eggs; no evidence existed of the service sire causing splitting of the zygote after fertilization, in the case of monozygotic twins (Johansson et al., 1974); fertility was not the primary focus of this research; any effect on fertility was assumed to be included in the residual effect; and the direct effects of sire of the calf should be independent of the maternal effects of the sire of the cow.

\section{Estimates of Variance Components and Genetic Trends}

Based on previous research, the most parsimonious model for the analysis of a binomial variable such as twinning rate is a threshold model (Gianola, 1982) with herd-years and sires of cows as random effects (Ron et al., 1990; Abdel-Azim and Berger, 1999). The linear and threshold animal model analyses and linear and threshold sire model analyses were run using a REML method and the average information algorithm of the MATVEC program (Wang et al., 2001) to obtain variance components and heritabilities of twinning rate in the first, second, and third parities. In addition, for sire models, the PTA for a sire was considered to be the sire effect, and heritability estimates $\left(h^{2}\right)$ were calculated as

$$
h^{2}=\frac{4 \sigma_{s}^{2}}{\sigma_{s}^{2}+\sigma_{e}^{2}},
$$


where $4 \sigma_{s}^{2}$ is the additive genetic variance and the denominator is the total phenotypic variance. Genetic trends were obtained by regressing yearly mean estimates of breeding values on year of birth. In addition, phenotypic trends were estimated using the linear regression of average phenotypic values on calving year.

\section{RESULTS AND DISCUSSION}

\section{Descriptive Analyses}

Rate of twinning in different parities from data set is given in Figure 1. The average twinning rate was $3.01 \%$ and the frequency of twinning increased from $1.10 \%$ in parity 1 to $4.50 \%$ in parity 4 and greater (Figure $1)$. The average annual phenotypic trends obtained from fitting the linear regression of annual mean twinning rates at parities 1,2 , and 3 were significant $(P<$ $0.001)$, and their corresponding values were -0.0003 $\pm 0.00005,-0.0006 \pm 0.0001$, and $-0.0009 \pm 0.0001$, respectively. Therefore, phenotypic rate of twinning decreased slightly from 1991 to 2007 for the first, second, and third calvings (Figure 2). For first-parity cows, a maximum frequency of twinning was observed in January through April, and second- and third-parity cows showed peaks in July through September. Similarly, Silva del Río et al. (2007) reported that the greatest twinning rate was observed in summer months compared with other seasons. Consistent with the result of this study for first-parity cows and contrary to the results obtained for second- and third-parity cows, Johanson et al. (2001) reported that the incidence of twins was highest in April through June, at 5.88\%, and lowest in October through December, at $4.23 \%$. The seasonal variation in reported twinning rates could be explained by variation in the ambient temperature. Nielen et al. (1989) speculated that photoperiod, nutritional flush- ing, or both affect the seasonal variation in twinning. Although calving season is included in our model, the real impact of season is at the time of conception or shortly thereafter. The results of this study also showed a relationship between higher incidences of twinning and the time of the year associated with higher milk production.

Consistent with our results, previous studies reported an increasing trend for twinning with parity (Johanson et al., 2001; Silva del Río et al., 2007; Ghavi HosseinZadeh et al., 2008). Reasons for a phenotypic increase in twinning over parity may be that older cows are more likely to ovulate several oocytes (Cady and Van Vleck, 1978). In this study, a greater increase in reported twinning rate at each calving year was observed for lactating cows compared with nonlactating heifers, and this result was consistent with our previous study (Ghavi Hossein-Zadeh et al., 2008). Lactating dairy cows are at a greater risk for twinning because of their greater occurrence of multiple ovulations compared with nonlactating heifers (Silva del Río et al., 2007).

\section{Variance Components and Genetic Correlations}

Estimates of variance components in the first, second, and third parities by linear animal model, linear sire model, threshold animal model, and threshold sire model are shown in Table 2. The estimated genetic and phenotypic correlations among twinning rate in the first, second, and third parities resulting from different models of analysis are shown in Table 3. Heritability estimates for twinning rate derived from the analysis of threshold models were greater than the corresponding estimates from linear models. In addition, heritability estimates were greater for twinning in the first parity than in the second and third parities when using both linear and threshold models of analysis. The heritabil-

Table 3. Estimates of genetic and phenotypic correlation for twinning rate between parities 1,2 , and 3 with different models of analysis ${ }^{1}$

\begin{tabular}{lllrl}
\hline Model of analysis & Trait 1 & Trait 2 & $r_{g_{12}}$ & $r_{p_{12}}$ \\
\hline Linear animal & Parity 1 & Parity 2 & 0.26 & 0.02 \\
& Parity 1 & Parity 3 & 0.22 & 0.02 \\
Threshold animal & Parity 2 & Parity 3 & 0.56 & 0.05 \\
& Parity 1 & Parity 2 & 0.43 & 0.03 \\
Linear sire & Parity 1 & Parity 3 & 0.06 & 0.01 \\
& Parity 2 & Parity 3 & 0.60 & 0.07 \\
Threshold sire & Parity 1 & Parity 2 & 0.23 & 0.03 \\
& Parity 1 & Parity 3 & 0.16 & 0.02 \\
& Parity 2 & Parity 3 & 0.62 & 0.05 \\
${ }^{1} r_{g_{12}}=$ genetic correlation between trait 1 and trait 2; $r_{p_{12}}=$ phenotypic correlation between trait 1 and trait 2.
\end{tabular}


Table 4. Summary of PTA of sires from the threshold sire model

\begin{tabular}{lcccccrc}
\hline Parity & Sires, $\mathrm{n}$ & \multicolumn{1}{c}{ Mean } & SD & Minimum & Maximum & Skewness & Kurtosis \\
\hline 1 & 5,166 & -0.0036 & 0.100 & -0.304 & 0.421 & 0.391 & 2.028 \\
2 & 4,825 & -0.0012 & 0.109 & -0.323 & 0.305 & -0.152 & 0.324 \\
3 & 4,111 & 0.0035 & 0.097 & -0.273 & 0.296 & 0.487 & 1.392 \\
\hline
\end{tabular}

ity estimates for twinning rate obtained from linear animal and linear sire models were similar. On the other hand, estimates of heritability obtained by the threshold sire model were greater than the corresponding estimates from threshold animal model analysis. Matos et al. (1997) fitted a linear sire model, threshold sire model, linear animal model, and threshold animal model to discrete reproductive traits of sheep. They discussed why sire models resulted in higher estimates of heritability compared with estimates obtained by animal models. They stated that this may have been due to some sires having daughters with consistently high or low ovulation rates, thus increasing the ratio of between-sire to within-sire variances. Further, it may be argued that some nonadditive components associated with reproductive traits may be partioned to sire variance in a sire model. This is magnified by multiplying sire variance by 4 to obtain heritability.

A summary of PTA of sires from the threshold and linear model analyses is shown in Table 4 and Table 5, respectively. Sire PTA for twinning rate in the first, second, and third parities ranged from -0.30 to 0.42 , -0.32 to 0.31 , and -0.27 to 0.30 , respectively. Genetic correlations for twinning rate between parities 2 and 3 were greater than correlations between parities 1 and 2 , and parities 1 and 3. In general, genetic correlations of twinning rate between adjacent lactations were greater than for parity 1 with 3 .

Consistent with our results, Johanson et al. (2001) reported that the heritability estimates for twinning rates were $2.1 \%$ by the linear sire model analysis and $8.71 \%$ by the threshold model analysis. In addition, they reported that sire PTA for twinning rate ranged from 1.6 to $8.0 \%$. The means of sire PTA from the current study were generally lower than corresponding values from the report of Johanson et al. (2001). Similar to the results of the current study, Ron et al. (1990) reported that heritability estimates were higher by the threshold model analyses, as compared with the linear model analyses. Karlsen et al. (2000) reported that the heritability estimates for twinning rate in Norwegian cattle were 0.7 to $0.8 \%$ in the first parity and $2.8 \%$ in the second parity. Our heritability estimates for twinning rate in parity 1 were generally greater than the corresponding estimates from the report of Karlsen et al. (2000), but the heritability estimates for twinning rate in parity 2 obtained from the linear and threshold models of analysis were, respectively, lower and greater than in their report. Heritability estimates of twinning rate, when analyzed with a linear model, depend on the frequency of the trait (Gianola, 1982). It is therefore not straightforward to compare estimates from different populations. However, all previous estimates indicate that heritability of twinning rate reported on the observed scale is low. On the underlying scale, however, estimates have been found to be higher (Ron et al., 1990). Ghavi Hossein-Zadeh et al. (2006), in a simulation study, reported that the linear model has always underestimated true heritabilities but that threshold models did not show consistent trends. Although the threshold model may be trusted at higher levels of true heritability, it does not behave consistently at lower heritabilities. Contrary to the results of the present study, Karlsen et al. (2000) reported that the genetic correlation between twinning in the first and second parities was approximately 1 . Syrstad (1984) reported a corresponding genetic correlation of 0.6. The estimated genetic correlations between twinning rate in parities 1 and 2, and between parities 1 and 3 in the present study were lower than the report of Syrstad (1984), but the estimated genetic correlation between twinning rate in parities 2 and 3 was consistent with the report of Syrstad (1984). Theoretically, the genetic correlation between 2 binary traits estimated by the use of linear methodology is expected to equal estimates on the underlying scale (Gianola, 1982). Mäntysaari et al. (1991) found a slight downward bias for the genetic correlation at a low incidence level when using linear methodology.

Table 5. Summary of PTA of sires from the linear sire model

\begin{tabular}{lccccccc}
\hline Parity & Sires, $\mathrm{n}$ & Mean & SD & Minimum & Maximum & Skewness & Kurtosis \\
\hline 1 & 5,166 & 0.00012 & 0.003 & -0.017 & 0.021 & 0.114 & 8.97 \\
2 & 4,825 & 0.00014 & 0.007 & -0.023 & 0.026 & 0.52 & 1.142 \\
3 & 4,111 & -0.0002 & 0.007 & -0.022 & 0.025 & -0.052 & 1.319 \\
\hline
\end{tabular}


Table 6. Estimates of genetic trends for twinning rate per year at different parities from different models of analysis $^{1}$

\begin{tabular}{lcccr}
\hline Parity & Linear animal & Linear sire & Threshold animal & \multicolumn{1}{c}{ Threshold sire } \\
\hline 1 & $0.00007 \pm 0.000001$ & $0.00001 \pm 0.000001$ & $-0.0006 \pm 0.00002$ & $-0.0004 \pm 0.00004$ \\
2 & $0.0001 \pm 0.00001$ & $0.00004 \pm 0.000004$ & $-0.0006 \pm 0.00001$ & $-0.00006 \pm 0.0001$ \\
3 & $0.0002 \pm 0.00001$ & $0.0001 \pm 0.00001$ & $-0.0001 \pm 0.00001$ & $0.0003 \pm 0.0001$ \\
\hline
\end{tabular}

${ }^{1}$ All values were significant at $P<0.001$.

In the present study, such downward bias was observed for genetic correlations estimated from different models of analysis.

\section{Genetic Trends and Fixed Effects}

The average annual genetic trends for twinning rates at different parities obtained by fitting linear regression of the annual mean EBV on year of birth are shown in
Table 6. In addition, the mean EBV of cows and bulls by year of birth when using different models of analysis are given in Figures 3, 4, 5, and 6. There was a slightly increasing trend for twinning rate in parities 1, 2, and 3 over time with analyses of the linear animal and linear sire models, but the trend for twinning rate in parities 1,2, and 3 with analysis of the threshold animal model decreased over the years. There was a significant decreasing trend for twinning rate in parities 1 and 2

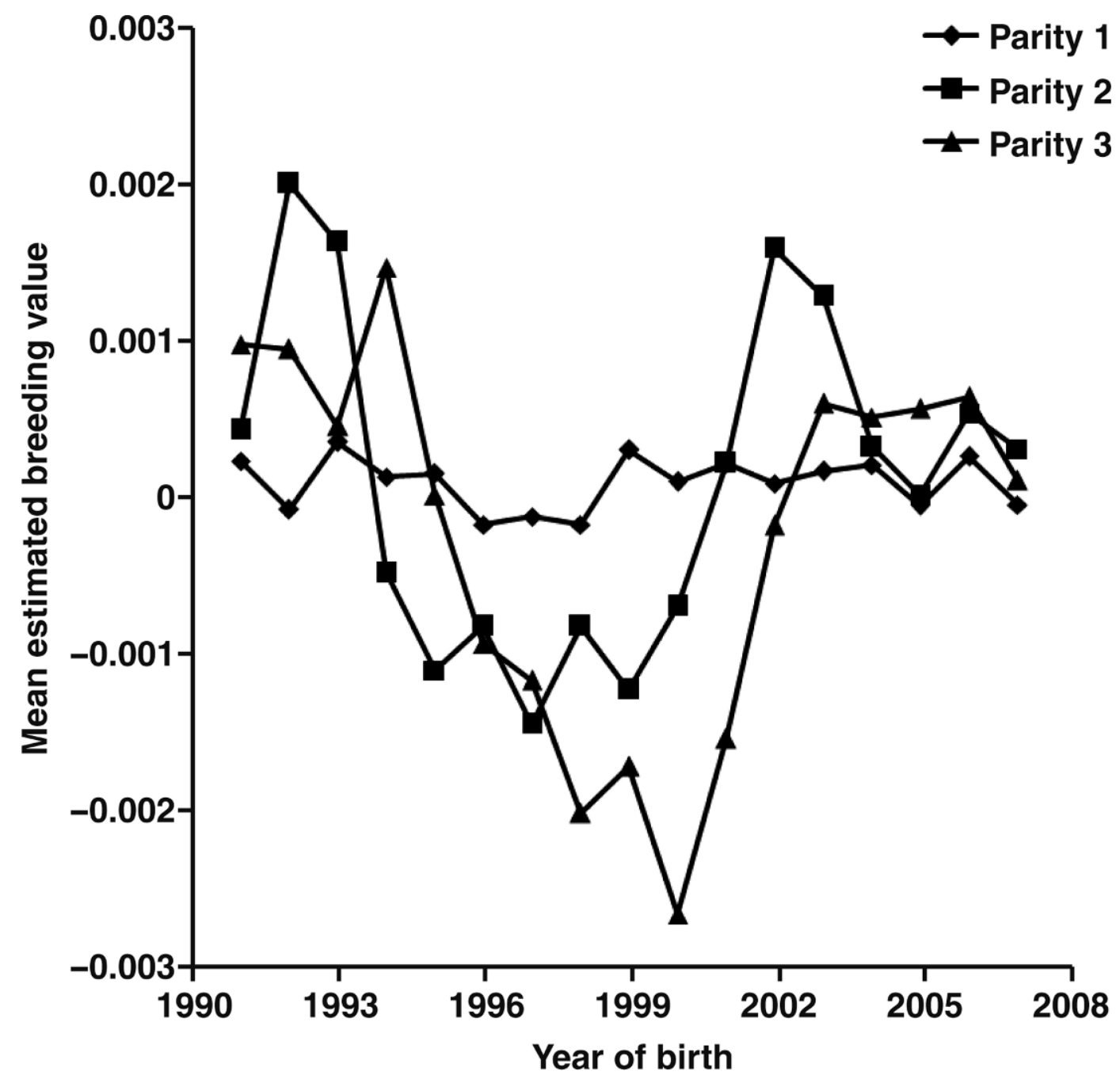

Figure 3. Mean EBV by year of birth obtained by linear animal model analysis for the first, second, and third parities. 


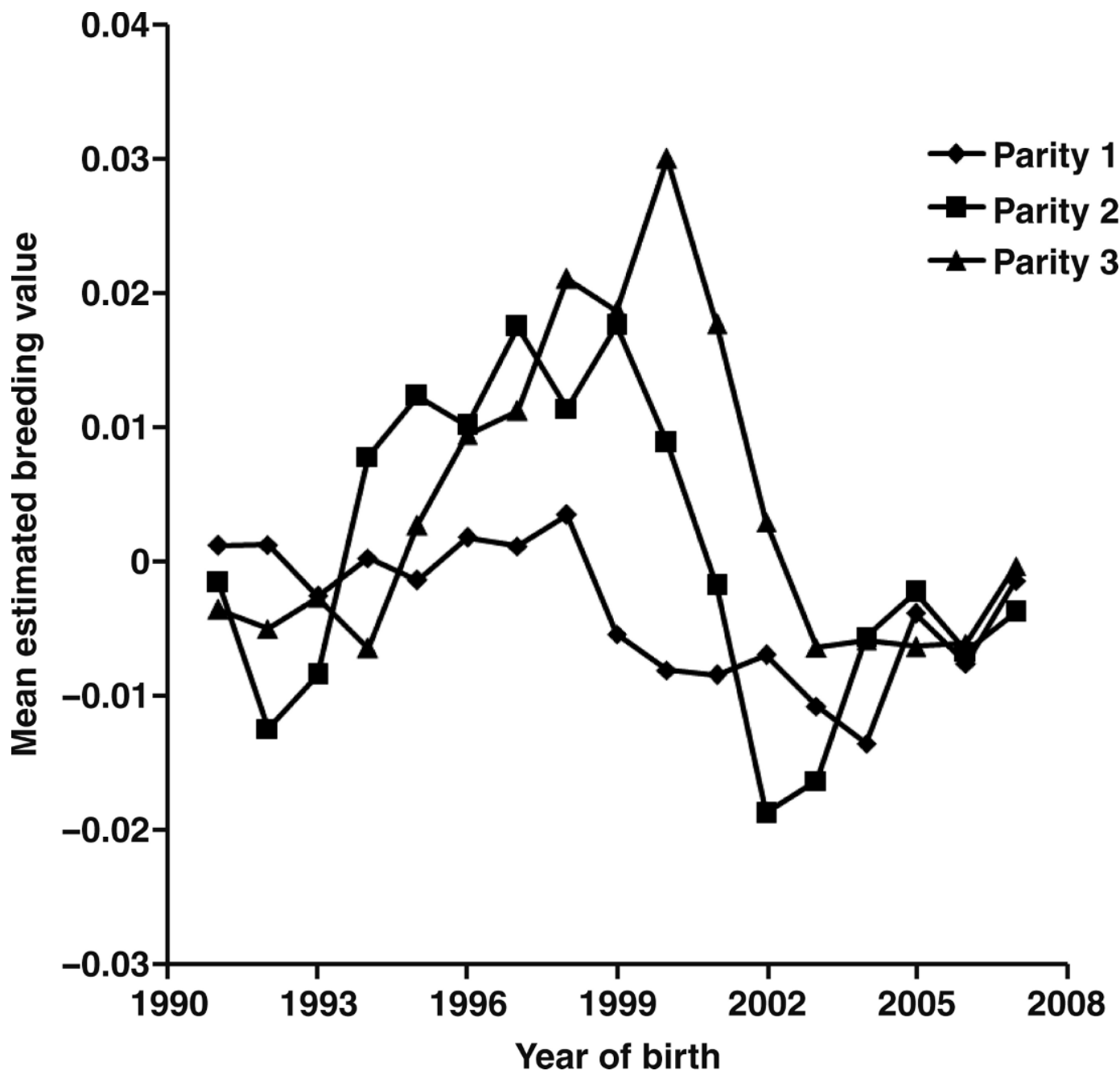

Figure 4. Mean EBV by year of birth obtained by threshold animal model analysis for the first, second, and third parities.

over time with analysis of the threshold sire model, but the genetic trend for twinning rate in parity 3 with this model of analysis was significantly positive. In general, genetic trends increased for twinning rate from parities 1 through 3 when using different models of analysis.

Solutions for age at calving for parities 1,2 , and 3 demonstrated that cows older at calving were more likely to have twins. Although the effect of calving interval on twinning rate was not significant, the longer interval between first and second parities, and between second and third parities, tended to be associated with lower twinning rate. For the interval between first and second parities, and between second and third parities, as the calving interval increased by $1 \mathrm{mo}$, twinning rate decreased by 0.179 and $0.180 \%$, respectively. Consistent with our result, Karlsen et al. (2000) reported that longer intervals had a negative effect on twinning rate in Norwegian cattle. Solutions for season of calving revealed more twins for cows calving in January through
April for first parity, and in July through September for second and third parities. Similarly, Karlsen et al. (2000) reported an increasing trend for twinning rate in first and second calvings of Norwegian cattle over the years. A possible explanation for the increasing genetic trend with some of the models is indirect selection on milk production, because twinning rate was found to have a positive genetic correlation with milk yield (Maijala and Osva, 1990). Although the goal of this study was not to investigate the relationship between twinning rate and milk yield, it seems that the observed increasing genetic trend for twinning rate with some of the models of analysis could be attributed to the positive increasing trend for milk yield in recent years. Razmkabir et al. (2006) reported a positive genetic trend for production traits, especially milk volume, in the Holstein dairy cattle of Iran in recent years. Improved nutrition might also be an important factor influencing both production and twinning rate. Hendy 


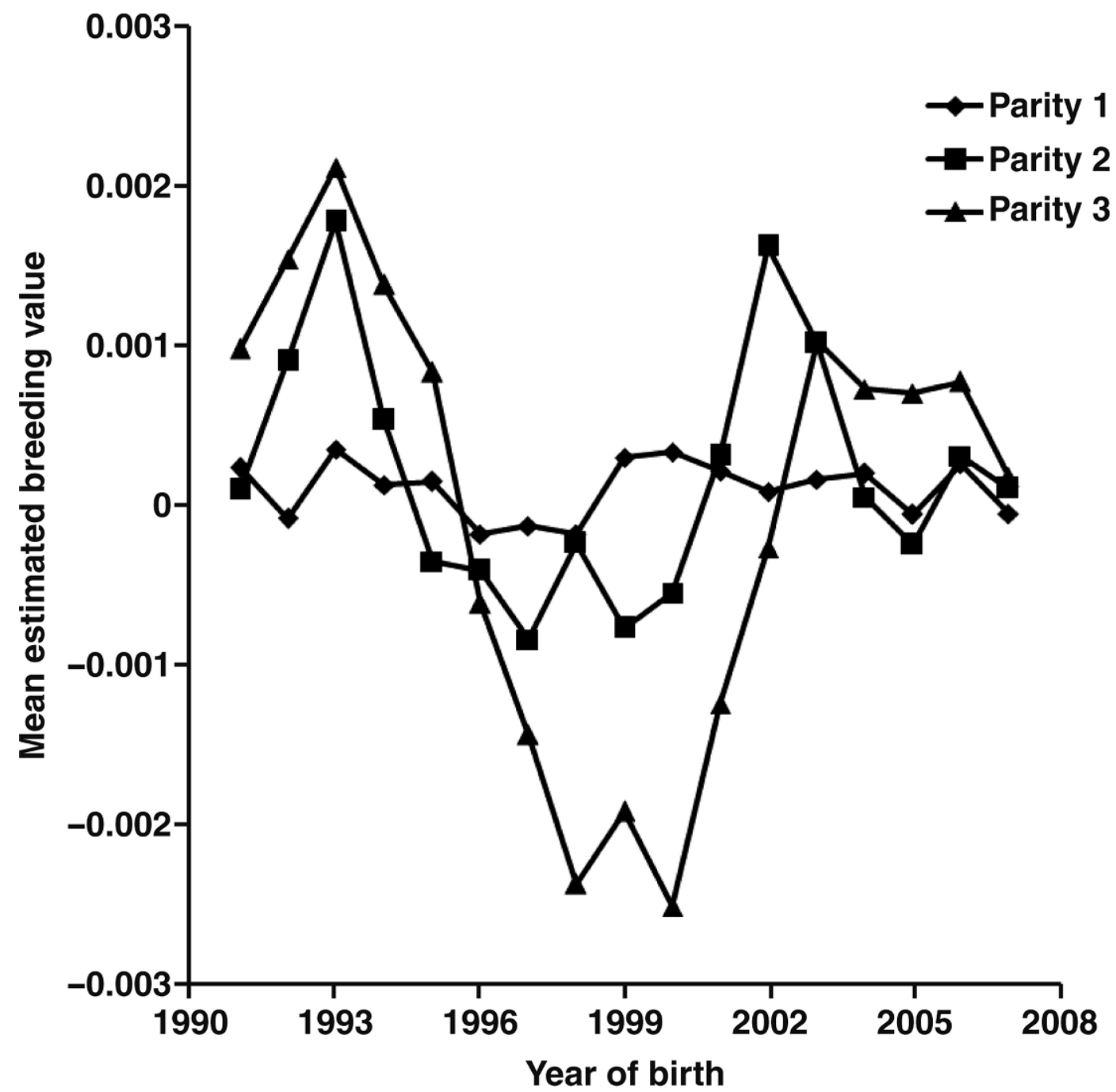

Figure 5. Mean EBV of bulls by year of birth obtained by linear sire model analysis for the first, second, and third parities.

and Bowman (1970) concluded in their review that an increase in the quality and quantity of feed will improve fertility, and presumably the manifestation of twinning, in a cow genetically predisposed to twinning.

\section{CONCLUSIONS}

The overall twinning rate was $3.01 \%$ and the frequency of twinning increased with parity. The phenotypic rate of twinning decreased from 1991 to 2007, for first, second, and third parities. The effectiveness of threshold models was previously compared with other linear models. However, we made a more complete comparison of these models for the trait of twinning. To rank sires for twinning rate, we recommend using the threshold sire model because it resulted in higher heritability compared with all other models. The threshold animal model may be used in selection programs in which cows are to be genetically ranked for twinning. Phenotypic averages of twinning in parities 2 and above are significantly higher than that in the first parity. However, the higher heritability of twinning in the first parity shows that higher potential exists for selecting animals for or against twinning based on their firstparity records. This is an advantage attributable to the reduced generation interval.

\section{ACKNOWLEDGMENTS}

The authors thank 2 anonymous reviewers for their constructive comments on earlier versions of this manuscript. In addition, the authors thank Mike Schutz for constructive editing of this manuscript. 


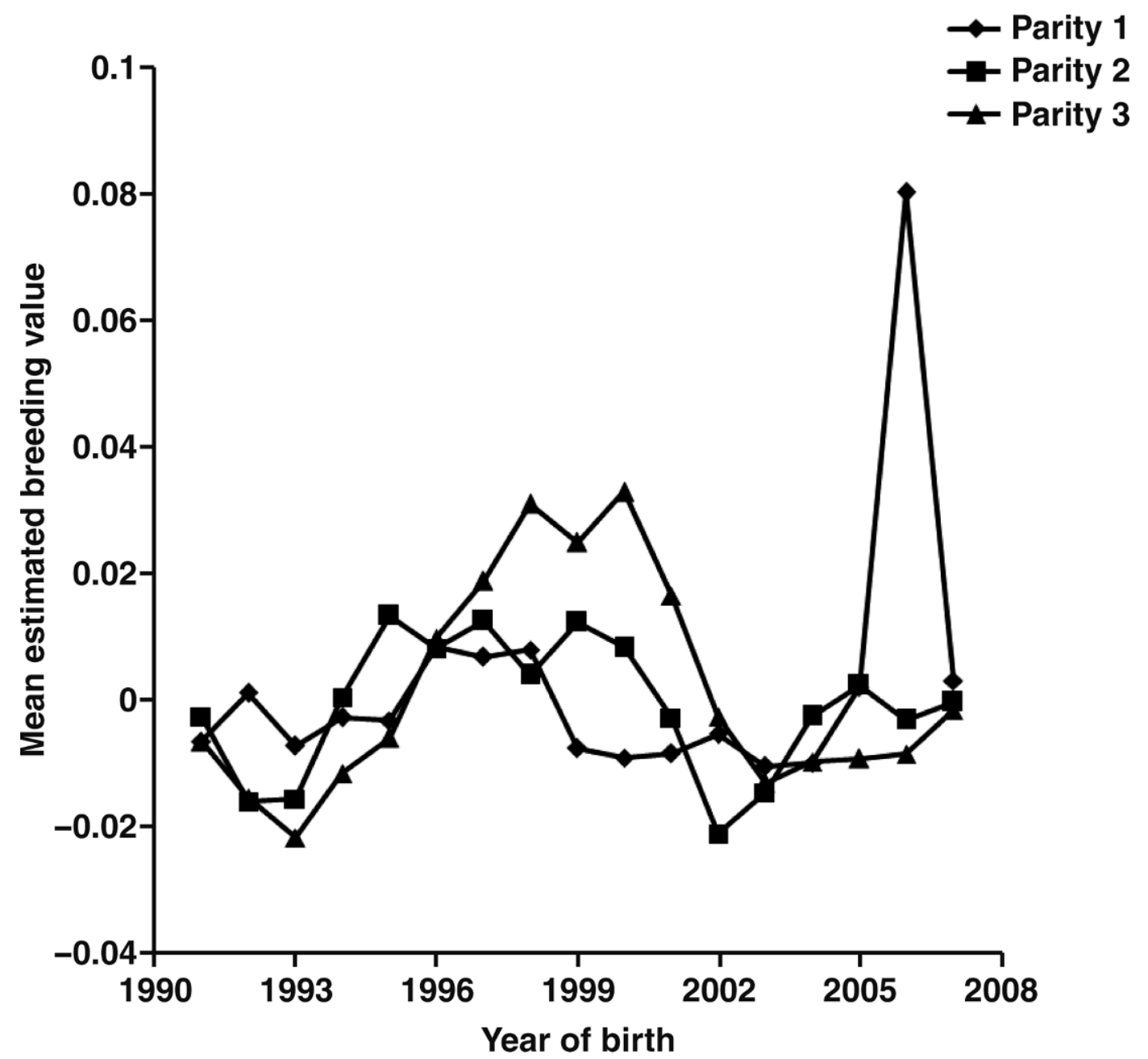

Figure 6. Mean EBV of bulls by year of birth obtained by threshold sire model analysis for the first, second, and third parities.

\section{REFERENCES}

Abdel-Azim, G. A., and P. J. Berger. 1999. Properties of threshold model predictions. J. Anim. Sci. 77:582-590.

Cady, R. A., and L. D. Van Vleck. 1978. Factors affecting twinning and effects of twinning in Holstein dairy cattle. J. Anim. Sci. 46:950-956.

De Vries, A., M. Overton, J. Fetrow, K. Leslie, S. Eicker, and G. Rogers. 2008. Exploring the impact of sexed semen on the structure of the dairy industry. J. Dairy Sci. 91:847-856.

Echternkamp, S. E., K. E. Gregory, G. E. Dickerson, L. V. Cundiff, R. M. Koch, and L. D. Van Vleck. 1990. Twinning in cattle II: Genetic and environmental effects on ovulation rate in puberal heifers and postpartum cows and the effects of ovulation rate on embryonic survival. J. Anim. Sci. 68:1877-1888.

Fricke, P. M. 2001. Review: Twinning in dairy cattle. Prof. Anim. Sci. 17:61-67.

Fricke, P. M., and M. C. Wiltbank. 1999. Effect of milk production on the incidence of double ovulation in dairy cows. Theriogenology 52:1133-1143.

Ghavi Hossein-Zadeh, N., A. Nejati-Javaremi, S. R. Miraei-Ashtiani, and H. Kohram. 2008. An observational analysis of twin births, calf stillbirth, calf sex ratio, and abortion in Iranian Holsteins. J. Dairy Sci. 91:4198-4205.
Ghavi Hossein-Zadeh, N., A. Nejati-Javaremi, S. R. Miraei-Ashtiani, and H. Mehrabani-Yeganeh. 2006. Effect of threshold nature of traits on heritability estimates obtained by linear model. 8th World Congr. Genet. Appl. Livest. Prod., Belo Horizonte, Minas Gerais, Brazil. Brazilian Society of Animal Improvement.

Gianola, D. 1982. Theory and analysis of threshold characters. J. Anim. Sci. 54:1079-1096.

Gregory, K. E., S. E. Echternkamp, G. E. Dickerson, R. M. Koch, and L. D. Van Vleck. 1990. Twinning in cattle I: Foundation animals and genetic and environmental effects on twinning rate. J. Anim. Sci. $68: 1867-1876$

Hendy, C. R. C., and J. C. Bowman. 1970. Twinning in cattle. Anim. Breed. Abstr. 38:22

Johanson, J. M., P. J. Berger, B. W. Kirkpatrick, and M. R. Dentine. 2001. Twinning rates for North American Holstein sires. J. Dairy Sci. 84:2081-2088.

Johansson, I., B. Lindhe, and F. Pirchner. 1974. Causes of variation in the frequency of monozygous and dizygous twinning in various breeds of cattle. Hereditas 78:201-234.

Karlsen, A., J. Ruane, G. Klemetsdal, and B. Heringstad. 2000. Twinning rate in Norwegian cattle: Frequency, (co)variance components, and genetic trends. J. Anim. Sci. 78:15-20.

Kinsel, M. L., W. E. Marsh, P. L. Ruegg, and W. G. Etherington. 1998. Risk factors for twinning in dairy cows. J. Dairy Sci. 81:989-993. 
Kirkpatrick, B. W. 2002. Management of twinning cow herds. J. Anim. Sci. 80(E Suppl. 2):E14-E18.

Maijala, K., and A. Osva. 1990. Genetic correlations of twinning frequency with other economic traits in dairy cattle. J. Anim. Breed. Genet. 107:7-15.

Mäntysaari, E. A., R. L. Quaas, and Y. T. Gröhn. 1991. Simulation study on covariance component estimation for two binary traits in an underlying continuous scale. J. Dairy Sci. 74:580-591.

Matos, C. A., D. L. Thomas, D. Gianola, R. J. Tempelman, and L. D. Young. 1997. Genetic analysis of discrete reproductive traits in sheep using linear and nonlinear models: I. Estimation of genetic parameters. J. Anim. Sci. 75:76-87.

Nielen, M., Y. H. Schukken, D. T. Scholl, H. J. Wilbrink, and A Brand. 1989. Twinning in dairy cattle: A study of risk factors and effects. Theriogenology 32:845-862.

Razmkabir, M., A. Nejati-Javaremi, M. Moradi-Shahrbabak, A. Rashidi, and M. B. Sayadnejad. 2006. Estimation of genetic trends for production traits in Holstein cattle of Iran. 8th World Congr. Genet. Appl. Livest. Prod., Belo Horizonte, Minas Gerais, Brazil.

Reid, J. T., O. D. White, R. Anrique, and A. Fortin. 1980. Nutritional energetics of livestock: Some present boundaries of knowledge and future research needs. J. Anim. Sci. 51:1393-1415.
Ron, M., E. Ezra, and J. I. Weller. 1990. Genetic analysis of twinning rate in Israeli Holstein cattle. Genet. Sel. Evol. 22:349-360.

Silva del Río, N., S. Stewart, P. Rapnicki, Y. M. Chang, and P. M. Fricke. 2007. An observational analysis of twin births, calf sex ratio, and calf mortality in Holstein dairy cattle. J. Dairy Sci. 90:1255-1264.

Syrstad, O. 1974. Genetic aspects of twinning in dairy cattle. Acta Agric. Scand. 24:319-322

Syrstad, O. 1984. Inheritance of multiple births in cattle. Livest. Prod. Sci. 11:373-380.

Van Vleck, L. D. 1971. Estimation of heritability of threshold characters. J. Dairy Sci. 55:218-225.

Van Vleck, L. D., and K. E. Gregory. 1996. Genetic trend and environmental effects in a population of cattle selected for twinning. J. Anim. Sci. 74:522-528.

Wang, T., R. I. Fernando, and D. S. Kachman. 2001. MATVEC User's Guide. Department of Biometry, University of Nebraska, Lincoln.

Wiltbank, M. C., P. M. Fricke, S. Sangsritavong, R. Sartori, and O. J. Ginther. 2000. Mechanisms that prevent and produce double ovulations in dairy cattle. J. Dairy Sci. 83:2998-3007. 